\title{
Defining the Role of Women in the Future of Political Leadership in the Middle East
}

\author{
Nasim Basiri ${ }^{1}$
}

\begin{abstract}
Throughout the years and more recently, dictatorial governments have often posed challenges to women in the Middle East, such as in Saudi Arabia, where woman are still not allowed to drive. Although governments have exercised their power to restrict women from doing certain activities and leadership.If we take a look back at the revolutionary Arab Spring, women were a driving force in expressing their voice through the protests and creating an unprecedented impact to shift the status quo in the Middle East. In the early phase of the Arab Spring, women played a pivotal role in supporting the protests against tyranny and ensuring they played an active part in the protests. Women in the Middle East have often been subject to discrimination regardless whether or not they are oppressed.

This paper evaluates the efforts of women and the current events that are developing a new face for Middle Eastern women and their role in the future of political leadership in the twenty-first century.

The paper also indicates that women within the Middle East have full potential to become a serious and powerful force within their society if they will fully attach on to the idea of becoming serious actors. More importantly, once they do this and they impact their role within the family, they will then gradually impact social change within their country. What is important within this process is the idea that they continue on the path of fighting for their liberation and change, because all of these spears are interconnected for women to become fully liberated within a society they have to be able to be fully liberated within all of these spears. Finally, this paper discusses obstacles to women in Middle East politics and possible recommendations that will improve the overall levels of women's political leadership in the Middle East.
\end{abstract}

Keywords: Women, Leadership, Politics, Middle East, Empowerment.

\section{INTRODUCTION}

'The women's movement...is the detonator which will explode the neopatriarchal society from within. If allowed to grow and come into its own, it will become the permanent shield against patriarchal regression, the cornerstone of future modernity.' (Sharabi, 1998)

Recent decades have witnessed growing demands in many countries for the inclusion and empowerment of more women in both elected and appointed office. Policies designed to achieve this objective have been implemented in a wide range of countries around the world including in Morocco, Jordan, Pakistan, Bahrain, India, South Africa, Bangladesh, and Tanzania and new initiatives 1 Nasim Basiri: College of Arts and social Sciences, Osmania Road, Hyderabad,Telengana State, India E_mail: nasimbasiri@gmail.com | Political Sciences Researcher 
are currently being undertaken in Afghanistan and Iraq. These developments highlight the need to consider issues of women's representation in design of new constitutions and electoral systems, and the most appropriate institutional arrangements that could achieve the inclusion of more women in both elected and appointed office.

These reforms are particularly urgent in the Middle East, where women continue to lag far behind men in political leadership positions, and successful initiatives can contribute greatly towards greater democratization and good governance in these societies (IPU, 2003).

In the larger context of development and better governance, the study of how women's political participation can be improved is of the utmost importance, and this is just as true for the Middle East as it is for the rest of the world. Not only does this topic warrant rigorous academic attention, the implications offer greater insight into the hindrances and benefits of increased penetration of women in political leadership. "Increasing both the level and quality of their participation, especially at the political and policy levels, has been a major plank of the international women's movement, which has consistently drawn attention to it and lobbied for it at national and international forums." In short, a study like this is important because it could initiate a larger, concerted effort to better understand how women in Middle East and the Arab world could become greater players in the politics of their nations and help to conceptualize strategies for implementation.

In a region witnessing such political ferment and grave socio-economic conditions, Middle Eastern women have had to create their own path into the public sphere. Women's participation in the labor force in the region is generally low, but their political participation whether in appointed or in elected positions is even lower. There have been some breakthroughs during the past decade in both quantitative and qualitative terms, as well as in terms of more concerted efforts to achieve increased participation, yet the obstacles such efforts face appear to be much greater than they are in other regions.

The difficulties faced in aligning national legislation with the stipulations of the Convention on the Elimination of All Forms of Discrimination Against Women (CEDAW) in Middle Eastern states as well as the Arab world states that have ratified the agreement stand out as the most striking example of the underlying tensions that exist regarding the advancement of women.

This is not to say that there are not ample resources to use for such a study but that there is significantly less secondary resources to use for such a study. Having resorted to obtaining information from different books and journals on women and politics the result has been an in-depth analysis of women in the region and the complexities involved in politics, as well as a series of recommendations to 
improve women's participation in regional and national politics.

This work is not prescribing what is good for women in the Middle East and Muslim countries; it is describing the necessary conditions for women to participate in what is gradually becoming the next phase of political advancement.

\section{SOCPE OF STUDY}

The parliamentary level of government is attractive for the purposes of this work because it presents a level of government that is present in all the countries concerned. It is no surprise that the different types of government in the Middle East, everything from democracies to republics to monarchies to authoritarian regimes, are of various hues and calibers, but that they all share parliamentary elements in which the national law-making depends on.

In addition, this study will cover countries in the Middle East and Arab Countries. The societies and peoples in these countries are of a wide variance do to characteristics like geography and culture that gives the Muslim world its multifaceted character.

The recommendations to be made in the latter part of this work are to act as policy guides, rather than ultimate objectives that if not carried out or followed will spell disaster.

This means that the recommendations made here, while comprehensive and functional, are not the only possible avenues to achieving the desired goal of incorporating women in a greater share of the decision-making processes of national governments in Muslim countries. This point must be understood because of the heterogeneity of the Arab and Muslim world, in that some recommendations will work better in some states than others.

\section{THEORETICAL FRAMEWORK}

Many Arab states are considering reforms to include more women in elected and appointed office. This issue is important since any exclusion of women leaders may have significant consequences for the articulation of their interests on the public policy agenda, as well as for the democratic legitimacy of legislative bodies and executive agencies. Initiatives expanding democratic elections in Middle East states provide a critical opportunity to strengthen human rights in general, and to improve women's rights in particular. Many countries around the globe have used positive action strategies designed to bring more women into elected leadership positions. By electoral law, about a dozen countries worldwide have reserved a certain number of parliamentary seats for women in the lower 
house of the national parliament. This strategy has been used for the lower house of the national parliament in Morocco, Jordan, Bangladesh, Pakistan, Botswana, Taiwan, Lesotho, and Tanzania. Reserved seats have also been adopted for the new Afghanistan constitution and positive action strategies are being considered in Iraq (Norris, 2004). At the local level, as well, in India 33 percent of seats on local municipal councils are reserved for women, bringing thousands of women into local office. This strategy likely to be particularly important in political systems where gender quotas cannot be implemented through party organizations and party rules. The effective implementation of reserved seats depends upon multiple detailed factors, including:

- How the statutory mechanisms are put into practice,

- The proportion or number of reserved seats for women specified by law,

- Whether the reserved seats are filled by appointment or election,

- If appointed, who selects nominees,

- How the use of reserved seats interacts with the electoral system.

\section{Contemporary issues: executive women in political office}

The news is littered with facts and figures of women increasingly taking the helm of the social, economic and political aspects of their nations. Notable high profile women in political and civil office include Asha-Rose Migiro (Deputy SecretaryGeneral of the UN) and Nancy Pelosi (Former Speaker of US Congress), and these are only a few to mention.

Women being elected and nominated for such positions are indeed a sign of the times we live in, for it is hard to imagine them occupying such offices a few decades ago. It is becoming the norm that women are increasingly taking such positions without societal uproars. It is equally notable that the credentials and abilities of these women are rarely challenged or questioned when they are chosen or elected for these positions. These developments should not be taken for granted since it has taken decades to reach this point and because many of these achievements are still restricted to mostly women in the developed world who are regularly in the media's limelight.

In terms of women heads of state, there are presently many who are heading their governments, either as presidents or prime ministers in Ireland, Latvia, Finland, Philippines, New Zealand, Mozambique, South Korea, Germany, Jamaica, Bangladesh, Liberia and Chile and etc.

These women leaders are at the highest echelon of political power and it may be said that it is reflective of the progressive nature of the changing times. Of course, this number only represents $6 \%$ of the total number of countries 
presented in the United Nations. It is also another issue whether the policies of their governments are effectively sympathetic to the issue of women in politics (B. Akande, 2007). This is because the few women that do rise to top positions in their political parties do so through complex political maneuverings and log-rolling practices, which are privy only to those in tight political circles, bureaucrats, and lobbyists who are almost always men.

Moreover, countries in the Middle East are also benefiting from the presence of women in the national cabinets because appointments to this level of the executive branch have been on the rise in recent years. According to the IPU women have made headway in the cabinets of various countries in the region, especially where such progress would not have been excepted only a few years ago - "Women are slowly emerging as political leaders in a region that has long been a bastion of male power. Where women have not been able to win direct election to Parliament, the political leadership has explored other avenues for increasing their participation, most notably through appointments, as in Bahrain, Kuwait and the UAE. Once invisible, women are gradually realizing their political potential and their concerns are beginning to be addressed in the political arena" (IPU, 2014).

An opposing view would be that these women leaders, while holding the highest political offices, are the exception because their governments are by no means gender balanced, and their rise to power should not be confused with increased women's participation in politics. Since looking at women at the top echelon of power is not a true reflection of women's involvement in the political realm, exploring the contributions of women at the parliamentary level is probably the best means to gauge their contributions to society. This is because national legislatures are responsible for the laws of the land, they are elected by the majority of the people, and the high numbers of parliamentary seats are more representative than any other branch of government (Judiciary and Executive). Thus, the parliament could be seen as an optimal forum for women to increase their political participation.

\section{STATUS OF WOMEN IN POLITICS}

Among other things the role that law plays in many Muslim countries cannot be discounted in the larger context of political development. In their book on Women and Power in the Middle East, editors Suad Joseph and Susan Slyomovics recognize that the relationship between women and their role in society is greatly affected by their status in the laws of a nation. Strictly speaking, family law in most Muslim countries is solely in the realm of religious institutions, and 
not in separate legal entities like a national court. As a matter of fact, Joseph and Slyomovics argue that this pattern of having family courts and religious institutions as one powerful entity may indeed be a serious impediment to the development of women's status in Muslim societies: 'by placing family law in the domain of religious institutions, Middle Eastern states have given control over issues that dramatically affect women to institutions that are gender biased. Clerics - Jewish, Christian, or Muslim - are all male, and their hierarchy is quite patriarchal'. This essentially means that the status of women in many of these societies is molded by predominantly male-dominated institutions that govern all aspects of women's lives, including politics.

This is an important argument in that it sheds light on the status of women in most Muslim countries because it shows that the laws that govern women in Muslim countries overwhelming favor the conventional male-dominated legal system. This should come as no surprise since this was also the predominant system in the rest of the world before the advent of more liberal and open legal systems that became the hallmark of the twenty first century. Notwithstanding, the lesson that we should take from this observation is that the legal systems in many Muslim countries have indeed failed to keep abreast of what we have come to except of the laws of contemporary states. Case in point, Tunisia and Turkey are the only two Muslim countries in the region that have a separate civil family code (Pew Research Center, 2013). This means that family law is not within the scope and authority of religious institutions, but by civil courts specifically established to handle such cases.

\section{OBSTACLES TO WOMEN IN MIDDLE EAST POLITICS}

What is being inferred here is that for various cultural and religious circumstances may actually stress the pressures on women to adhere along patriarchal lines in their lives. It should hence come as no shock that such patriarchal patterns are replicated in the political arena in the Middle East, and act as another barrier to the women's increased involvement in politics.

\subsection{A Public-Personal Rupture}

Middle Eastern social norms and attitudes which have eulogized women's role in the private sphere while creating barriers to their participation in the public one remain an important obstacle. The World Bank sees gender roles and dynamics within the household as being shaped by a traditional gender paradigm that presumes that the most important contribution women can make is to family and 
society, as homemakers and mothers. While the World Bank put this paradigm forward to explain the low rates of female participation in the labor force, it can easily be applied to explaining their low rates of participation in political life or public life in general. This gender paradigm is based on four elements:

1. 'The centrality of the family, rather than the individual, as the main unit of society. This emphasis on the family is seen as justification for equivalent, rather than equal, rights'.

2. 'The assumption that the man is the sole breadwinner of the family'.

3. "A "code of modesty" under which family honor and dignity rest on the reputation of the woman. This code imposes restrictions on interaction between men and women.

4. 'An unequal balance of power in the private sphere that affects women's access to the public sphere. This power difference is anchored in family laws (World Bank, 2003).

Recent research on Middle Eastern women's political leadership has concluded that 'women are not active in politics because politics is not a safe and secure place', calling for a focus on human security to ensure that women can participate freely without threats and coercion (Hamzeh,2004). While such a new angle for analyzing Middle Eastern women's political participation could lead to certain improvements in women's levels of participation, it is rather simplistic to think that this would be enough to turn the tables and bring women's political leadership to its full measure.

\subsection{A Male-Dominated Society}

Patriarchy is still a major force barricading Middle Eastern women's progression. A combination of patriarchy, conservative religious interpretations and cultural stereotyping has built a very strong psychological barrier among Middle Eastern populations regarding women's participation in the society. The hierarchical, patriarchal tribal structure of several Middle Eastern societies may be another cause that contributes to this state of affairs. Eventually, an acceptance of the status quo and possibly an unconscious fear of change have become a major struggle that has to be dealt with. Sharabi's concept of neo-patriarchy (Sharabi, 1988) in the region capably explains the conditions of patriarchy in Middle Eastern society that have been amplified and sustained in more modernized figures. Sharabi claims that the drive towards modernity in the region has strengthened the patriarchal norms and values; hence he looks at the oppression 
of women as the headstone of the neo-patriarchal system and their emancipation as an essential and important condition for overcoming it.

\section{RECOMMENDATIONS}

This section discusses possible recommendations that will improve the overall levels of women's political leadership in the Middle East, especially at the parliamentary level of government. These recommendations, though, could also act as a model for other regions that have low levels of women's involvement in politics, principally in the Middle East. In the context of low levels of women's political participation, it may be said that these recommendations are applicable to more than just the Middle East and Muslim countries, but taking into consideration the particularly low figures in the region the importance of these recommendations take on an even greater importance that makes their implementation even more imperative.

The recommendations are divided into categories that cover the three levels/ units of analysis: domestic, national and international. The decision to focus on three categories lies in the fact that no amount of research and detail can adequately cover all possible solutions to complex issues. Moreover, an exhaustive list of recommendations is not the goal here but to provide a framework, in which we can, first, conceptualize the matter of increasing political participation and leadership and, then, assess ways and methods in which to address this overarching problem. The recommendations are as follows:

\subsection{Education}

"While voting requires little education, in general, education is a vital tool for effective participation that is, making informed choices, contributing to public debates, or signing petitions, for example." This excerpt sufficiently conveys the message of why education is so vital to achieving the goal of bringing women into the political arena. The role of education is any society is without question vital to the development of that society - both in terms of individual and collective intellectual capacities. In 1995 the World Conference on Women declared that "investing in formal and non-formal education and training for girls and women, with its exceptionally high social and economic return, has proved to be one of the best means of achieving sustainable development and economic growth" (UN, 1995). Education could then be said to possess 'spillover' effects that carry over to other sectors.

In essence, in order to improve the role of women in the political arena 
there will need to be a complete overhaul of the way education is not only implemented, but also the way it is conceptualized. The reason for this lies in the truth that a major part of having women in the political arena requires that they are taught the same critical type of education that men and boys enjoy in these same societies. The issue of education in the Middle East and many Muslim countries is a threefold problem: lower than average levels of education, low levels of girl's education, and lack of critical education for girls.

Education in its strict sense should include more than just literacy rates or levels of conventional education (primary, secondary, and tertiary) - "Muslim women's emancipation needs to be approached from another direction besides education, namely, perceptual and attitudinal change.

\subsection{Quotas \& National Legislation}

The debate surrounding quotas is never a dull one, especially when a significant group or element stands to lose something in the process. This is usually the case in domestic politics because interests have been entrenched in various sectors of society and establishing a quota system may be perceived as eroding the power or influence of that group. The same argument has been used in respect to establishing a quota system for women in parliaments and the discourse is far from being resolved. Quotas are essentially legislative stipulations that allocate a certain percentage of parliamentary seats to a specific group - usually one that has up to that point been covertly or overtly excluded or discriminated against in the decision-making process. They may be groups based on ethnicity, religion, race, culture, region, or, in this case, gender. However, quotas are against the democratic spirit because they impose an artificial reserve system on the parliament.

\subsection{Regional Reform (Diplomacy \& the Arab League)}

The Convention on the Elimination of all Forms of Discrimination Against Women (CEDAW) institutionalizes the status of women as one of equality and upholds their of basic rights. The Convention came into force in 1979 and today has today been ratified by a total of 185 countries, although some states also have reservations .Most Muslim countries have ratified the convention, and of the 22 members of the Arab League, 19 are signatories of the convention, with Sudan, Somalia and Qatar opting out altogether (Mariappuram, 2015). The significance of this treaty stems from wide scope of human rights including legal and civil, in which all signatories have recognized and vowed to uphold in respect to the 
equality and non-discrimination of women - something that up until then had never been done before.

This effort is necessary because of the wide variance in women's political involvement in the decision-making process across the Middle East and the Muslim world. For instance, women in a Muslim country like Iran, Pakistan or Morocco are significantly more involved in politics than any of the Gulf States in the region. At a time when women are being trained as professionals like engineers, doctors, politicians, lawyers, and where many are performing at the highest levels of government in many developed and developing countries, this region is missing out on an immense opportunity to harness the abilities and talents of its women. It would indeed be an understatement to say that most societies are yet to recognize the importance of bringing women into their administrations and institutions. It should be the prerogative of the Arab League to usher in the twenty first century by changing not only the structure of the Arab League itself by updating its mission, but also its integral composition.

Furthermore, the need for laying the ground work for educational reform is necessary because much of the progress that has already been made is not as a result of policy planning or government foresight. This point is reiterated by Fatima Mernissi in the following passage from, Beyond the Veil, Male-Female Dynamics in Modern Muslim Society:

Women have gained many rights that were denied them before, such as the right to education, the right to vote and be elected, and the right to use non-domestic spaces. But an important characteristic of this nascent 'liberation' is that it is not the outcome of a careful plan of controlled nation-wide development. Neither is it the outcome of the massive involvement of women in the labor markets, coupled with organized women's movements. The partial, fragmented acquisition of rights by women in Arab-Muslim countries is a random, non-planned, non-systematic phenomenon, due mainly to the disintegration of the traditional system under pressures from within and without.

It is thus the objectives of these recommendations to ensure that whatever policies emerge in Middle Eastern nations are in fact as a result of careful state planning that is, expectantly, done within a regional framework. This matter also brings other issues into perspective because of the capacity and willingness of states to carry out such actions. Education, culture and national legislation are all themes that should be taken into account when considering such changes, since they are intertwined: women's education in certain fields yields their entry into governance, culture determines the people's perceptions, and legislation can act 
as a catalyst for societal change. Of the these recommendations put forward here, education presents a long-term, while quotas and regional reform are short-term solutions that can be implemented as long as the collective political will of the states to carry out such reforms is present. Another attractive feature of these recommendations is that they are in no way incompatible with or contradictory to Islamic beliefs, which further stresses their applicability to resolving these outstanding issues.

A final observation is that the relationship between women political leaders and the women's movement must be further developed into a mutually collaborative one. Mechanisms to improve and enhance this relationship need to be further studied and developed (Karam, 1999). Within the Middle East region, examples from North African countries such as Morocco, Tunisia and Algeria can be used to highlight how women politicians responded to legislative amendments demanded by the women's movement. However, given that in most Middle Eastern countries women politicians have not yet reached a critical mass, both women politicians and women's movements need to strategize together on how best to effect change within each country's set of priorities, opportunities and challenges.

\section{CONCLUSION}

This study illustrates that Middle Eastern women have challenges which are largely similar to their counterparts elsewhere in the world. Nevertheless, they seem to face challenges that are particular to the region. Political leadership development should especially focus on influencing and coaching skills. Indeed, Middle Eastern leaders could exert a great deal of influence by developing others according to their vision, with the use of subtle influencing tactics and adopting a shadow leadership style which may be more appropriate and effective in Middle Eastern context.

It is often the case that discussions on the political leadership status and delegation of Middle Eastern women tend to highlight the difficulties and challenges at the expense of presenting the more positive aspects or breakthroughs that have occurred during the recent years. This positive gain momentum is gaining strength; changes were taking place that promise a more prominent role and presence for Middle Eastern women. If Middle Eastern societies are to benefit fully from the winds of political reform that are currently sweeping the region, then women have to become an active part of these processes by asserting their full potential and efforts as the heralds of a better future. 


\section{REFERENCES}

B. AKANDE, ABDUL-RAHMAN . 2007. The evolution of women in middle eastern politics opportunities for women in parliament, http://fletcher.tufts. edu/,2007.

HAMZEH, ALIA, 2004. 'Leaders adopt reform plan'. Jordan times, 2004.

IPU.2014. WOMEN IN PARLIAMENT: 20 years in review, geneva, 2014.

KARAM, AZZA, 1999. 'Strengthening the role of women parliamentarians in the arab region: challenges and options', available at http:www.pogar.org/ publications/gender/karam1/karama.pdf

MARIAPPURAM , ROSAN .2015, outcomes of the convention on the elimination of all forms of discrimination against women (cedaw) in the arab world, city college of new york, 2015.

MERNISSI, FATIMA.1987. Beyond the veil, male-female dynamics in modern muslim society, indiana university press, usa, isbn: 0-253-31162-4

PEW RESEARCH CENTER. 2013. The world's muslims: religion, politics and society.2013, http://www.pewforum.org/2013/04/30/the-worlds-muslimsreligion-politics-society-overview/

NORISS, PIPPA. 2004. Women's representation in the middle east: evaluating positive action strategies, john $\mathrm{f}$. Kennedy school of government harvard university, 2004.

The inter-parliamentary union estimates that about 6000 women sit in parliament worldwide in march 2003 , representing $15.3 \%$ of all members. As is wellknown, women parliamentarians do best in the nordic nations, constituting $39 \%$ of $\mathrm{mps}$ in the lower house. The greatest gender inequality remains in arab states, where women are $6 \%$ of elected representatives, and women continue to be barred by law from standing for parliament in kuwait, qatar, saudi arabia, oman, and the united arab emirates. There have been some moves towards reforms in the region, for example in bahrain legal revisions allowed women to stand in elections for the first time in the may 2002 local elections, but none were successful in elections to the national parliament held five months later. See inter-parliamentary union. 2003. Women in national parliaments. Www.ipu.org

UN.1995. The united nations fourth world conference on women, beijing, china - september 1995.

SHARABI, HISHAM, 1988. Neopatriarchy: a theory of distorted change in arab society. New york: oxford university press, 1988.

SHARABI , 1988, op. Cit., p. 154.

WORLD BANK, 2003. Gender and development in the middle east and north africa: women in the public sphere. Washington, DC: World bank, 2003. 